\title{
BARBÁRIE ESTÉTICA E PRODUÇÃO JORNALÍSTICA: A ATUALIDADE DO CONCEITO DE INDÚSTRIA CULTURAL*
}

\author{
Belarmino Cesar Guimarães da Costa **
}

\begin{abstract}
RESU M 0: 0 trabalho busca, através da atualidade do conceito de indústria cultural, demonstrar as contribuições daTeoria C rítica para os estudos de comunicação, em particular, para a identificação do processo de heteronomia cultural, hierarquização dos artefatos e universalização depadrões estéticos. Toma como referência a produção jornalística para verificar, na construção da notícia, a ap ropriação da racionalidadetécnica e explora a questão da violência na perspectiva de que ela não se esgota com o enunciado da mensagem, mas deve ser compreendida também nas condições de sua produção. A estetização da realidade, a mediação tecnológica e a relação entre sensibilidade e experiência complementam a exposição.
\end{abstract}

Palavras-chave: T eoria C rítica; Indústria Cultural; Estética da Violência; N otícia; Formação Cultural.

Tem se tornado cada vez mais aguda a tensão formulada por H orkheimer e Adorno, no clássico Dialética do Esclarecimento, sobre a incongruência entre progresso técnico no setor de produção industrial da cultura e a regressão dos sentidos. D epois de meio século do aparecimento da expressão indústria cultural, para assinalar o equívoco de se supor que a cultura de massa emergente era uma expressão identificadora da espontaneidade da cultura popular, boa parte da produção de teóricos de comunicação passou a formular o argumento do envelhecimento desta categoria e da extemporaneidade da Teoria Crítica para produzir conhecimento no contexto das novas tecnologias, que combinam informática, virtualidade e hibridismo dos suportes.

* Trabalho aprovado para o XXIV Congresso Brasileiro de Ciências da Comunicação (Intercom), de 3 a 7 de setembro de 2001, em Campo Grande (M S).

* Professor e coordenador do Curso de Jornalismo (Faculdade de Comunicação) da Universidade M etodista de Piracicaba (U nimep). E-mail: bcgcosta@iepmail.unimep.br 
0 refluxo da Teoria Crítica, admitida na condição de método historicamente superado para produzir conhecimento na área de comunicação, é decorrente de um juízo falso: 0 de que estaria delimitada a um tempo que a crítica negativa era necessária para se opor às estruturas e governos autoritários. A pecha de apocalíptica, ahistória e idealista passou a ser uma mácula para supor o anacronismo da Escola de Frankfurt, ainda mais em admitir sua capacidade de intervir no contexto histórico das novas tecnologias de comunicação.

Em diversos textos, com destaque para Educação após Auschwitz, Adorno (1995) estabelece como necessário ao processo de emancipação da sociedade e do sujeito as lembranças das atrocidades do passado, que ainda persistem em nome do desenvolvimento tecnológico e científico. D e fato, as tranरformações empreendedoras de rupturas de espaço e tempo, em particular, nas revoluções dos transportes e das comunicações, que incidem na mudança da esfera pública e do sentido de realidade, representam conquistas que podem permitir a existência de uma sociedade mais esclarecida. Contudo, as esperanças depositadas no projeto humanista convivem, de forma ambivalente, com a exclusão tecnológica, com a desigualdade econômica e com a semiformação cultural, dentre outras que apontam para a ingenuidade de supor correspondência imediata entre progresso técnico e emancipação humana.

Estas reflexões, que resultam de pesquisas desenvolvidas desde 1991, quando foi criado o Grupo de Teoria Crítica e Educação, na Universidade Federal de São C arlos (U fscar), e que hoje continuam também na Universidade M etodista de Piracicaba (U nimep), procuram afirmar a validade da Teoria C rítica como referência para os estudos e pesquisas na área de comunicação, em particular, tomando-se como referência os teóricos da primeira geração do Instituto de Pesquisa Social, criado na Alemanha, na década de 1920. Adorno, Horkheimer, Benjamin e $M$ arcuse identificaram estruturas autoritárias, em particular, no contexto da comunicação na sociedade industrial, que ainda permanecem mascaradas pelo fascínio da técnica e sua mediação na sensibilidade e inteligibilidade humanas.

Este artigo, que resulta da intenção de inserir a Teoria Crítica no debate contemporâneo a respeito da cultura mediática e da crise da razão em criar uma sociedade nem sempre racional, toma como estrutura os seguintes momentos: 1. Trata da validade do conceito de indústria cultural na perspectiva de reafirmar 0 argumento deH orkheimer eAdorno de que ela representa uma ação de anti-Iluminismo; 2. Faz uma exposição a respeito da estética da barbárie presente nas estruturas de comu- 
nicação, em especial do jornalismo, quando constrói artefatos culturais que propendem à estetização da realidade e à exploração da violência; 3. D iscorre sobre os prejuízos que a mediação da técnica pode provocar no estatuto da sensibilidade e da experiência.

Esta análise recorre, portanto, aos fundamentos da Escola de Frankfurt, em particular, pela crítica imanente que faz da estrutura do sistema de comunicação social, tendo em conta a investigação histórica dos mass media, com enfoque na filosofia, nas ciências sociais e na questão da subjetividade. As novas tendências de teorização dos fenômenos da cultura mediática não podem colocar à margem a investigação estética, política e de crítica negativa exposta pelos frankfutianos. Isto também não significa retomar os clássicos fora de seus momentos históricos como se fosse possível separá-los de suas conjunturas de análise e incorporá-los sem mediação com a etapa presente do capitalismo tardio e da produção cultural.

\section{Revitalização do conceito de indústria cultural}

A categoria indústria cultural vem a público pela primeira vez em 1947, quando já se tornava visível a existência de um setor da produção da cultura comprometido com as estruturas de mercado. A utilização do rádio, do cinema e dos meios impressos existentes, como instrumentos de propaganda política de regimes autoritários, durante particularmente a ascensão do nazifascismo e na era stalinista, e a incorporação destes meios na perspectiva de valorização do American way of life fizeram com que Adorno e H orkheimer, nos EU A, país onde se encontravam exilados e que dispunham de uma indústria de informação e de entretenimento mais empreendedora e massiva, estabelecessem relações de proximidade entre autoritarismo econômico-político e fascismo cultural.

$\mathrm{N}$ a pesquisa de mestrado "O 'Estado' da educação na 'Folha' de jornal - Como os jornais de grande circulação abordam a questão educacional", desenvolvida na U fscar, entre 1991 a 1993, destacamos a importância da Teoria Crítica para os estudos da comunicação que, pela pecha de apocalíptica, uma terminologia criada por U mberto Eco, tem sido estigmatizada como superada. A obsolescência admitida decorre desta teoria não ser capaz de compreender as transformações do ambiente tecnológico, cultural e de integração global ocorridas, sobretudo, com a informatização da sociedade e do surgimento de suportes virtuais e híbridos, nas últimas décadas. 
Este exercício de retomada do conceito indústria cultural, tal como foi formulado pelos pensadores frankfurtianos, não significa deixar de compreender a modificação do ambiente técnico e das características hodiernas do processo de comunicação, mas tem o propósito de identificar a presença de estruturas autoritárias que permanecem e explicitar a contradição entre potencial técnico e arrefecimento da capacidade de julgar e de formular gostos estéticos autênticos. U ma metáfora se coloca ainda denunciadora dos rumos da técnica na sociedade. Trata-se daquela formulada por $\mathrm{H}$ orkheimer, no livro A eclipse da razão, que acusa o seguinte:

A criseda razão semanifesta na crisedo indivíduo, por meio da qual sedesenvolveu. A ilusão acalentada pela filosofia tradicional sobreosindivíduos esobrea razão a ilusão de sua eternidade - etá se di ssi pando. 0 indivíduo outrora concebia a razão como um instrumento do eu, exclusivamente $\mathrm{H}$ oje, eleexperimenta o reverso dessa autodeificação. A máquina expeliu o maquinista: está correndo cegamente no espaço. No momento da consumação, a razão tornou-se irracional e embrutecida.(H orkheimer, 1975, p. 19 - grifosnossos)

Esta representação do descontrole do homem sobre a racionalidade instrumental embutida na técnica não desapareceu e supõe retomar 0 argumento de Horkheimer e Adorno, que caracterizam a indústria cultural como aparatos técnicos que paradoxalmente mistificam a realidade, quando se supunha o potencial de emancipação nos progressos científicos e nas produções culturais tornadas disponíveis pela massificação. A perda do controle da máquina é um sinal da contradição entre a existência de uma sociedade que se firma na autonomia do sujeito, em sua capacidade de escolha e de busca do prazer e, ao mesmo tempo, a afirmação da heteronomia cultural, de cada consumidor se objetivar nas estatísticas da audiência. Eis a retomada do argumento: a massa é um elemento secundário, de cálculo; acessório da maquinaria (H orkheimer \& Adorno, 1990). U ma ilustração deste descontrole se verifica na relação entre índices de audiência e a pauperização da qualidade das mensagens televisivas.

O conceito de indústria cultural busca identificar a forma como a arte se submeteu à condição de mercadoria. Isto tem o peso de assinalar que mesmo que determinados artefatos culturais venham a ter isoladamente qualidades que se diferenciem dos padrões medianos, de forma articulada e sistêmica, constituem segmentos que buscam a integração do consumidor à lógica da circulação da mercadoria. A chave deste argumento está em reconhecer que a Teoria C rítica toma como referência de 
análise a estrutura dos sistemas de comunicação em sua incorporação pela dinâmica de expansão do capitalismo.

0 argumento de que este setor da produção promove a hierarquia das qualidades dos produtos culturais e, no conjunto, cria para cada um, de acordo com o seu nível, parecenos que não está fadado ao esquecimento. A segmentação de público com produções centradas em poucos emissores possibilita imaginar que esta realidade ainda não foi superada, mesmo com a existência de meios supostamente mais interativos de comunicação. A rede mundial de computadores, se permite pensar na existência de estruturas descentradas, aos poucos vem sendo também potencializada como mais um setor de produção articulado com outros da indústria cultural.

A heteronomia cultural, a transformação da arte em mercadoria, a hierarquização das qualidades, a incorporação de novos suportes de comunicação pelos setores que já detinham os meios de reprodução simbólica, no seu conjunto, apontam para a continuidade da administração da cultura. Em outras palavras, a dispersão do público-receptor e a impessoalidade no processo de comunicação, combinadas com o monopólio e o sistema de produção baseado na divisão do trabalho, fazem com que a ampliação deste setor da produção seja acompanhada pela apropriação silenciosa de um modelo de cultura que separa: quem produz de quem consome.

A hegemonia desta forma de produção cultural pode ser observada em manifestações que já foram identificadas e que continuam existindo, dentre elas: 0 caráter de montagem dos produtos; a capacidade destes prescrever a reação dos receptores; a reprodução técnica que compromete a autenticidade da obra de arte; o consumidor como objeto da indústria cultural; a falsa identidade entre 0 universal e 0 particular; a técnica como ideologia; o "novo" como primado manifesto do imediato e da busca calculada do efeito; a exploração da fraqueza do "eu" numa sociedade de personalidades debilitadas e que facilmente aderem a ideários autoritários.

\section{Jornalismo e violência: a estetização da realidade}

A descrença em torno da ideologia do progresso e a interpretação de que a sociedade industrial produziu formas complexas de dominação, que prescindem cada vez mais do uso manifesto da força, e que nos convida a uma adaptação fácil pela persuasão massiva, permeiam muitas discussões a respeito da indústria cultural. Pretendemos identificar um 
setor, o da informação jornalística, para abordar a contraposição entre fluxos de notícias e a falta de esclarecimento.

Sem que tenham aprofundado questões específicas da produção jornalística, H orkheimer e Adorno, não só na obra Dialética do esclarecimento, mas este último também na Teoria estética, deixam depreender que a produção de bens simbólicos, de qualquer setor da indústria cultural, assimila a técnica e a linguagem do meio responsável pelo seu aparecimento, de tal maneira que se torna impraticável teoricamente a ruptura entre forma e conteúdo; processos de recepção e produção industrial; mensagem e ideologia presente na técnica.

Uma categoria que assinala esta impossibilidade de separar mensagem da forma de sua produção se dá quando os teóricos frankfurtianos analisam a violência da sociedade industrial no momento de distração, através do uso da expressão "barbárie estética". Ela é um equivalente para dimensionar os prejuízos que a repetição, a exclusão do novo, o lazer como extensão da racionalidade do trabal ho provocam na formação.

$\mathrm{N}$ a tese de doutorado que defendemos na Faculdade de Educação da U nicamp, em 1999, com o título "Estética da violência: Jornalismo e produção de sentidos", buscamos localizar na prática jornalística e na produção da notícia formas de violência estética. Isto quer dizer: a informação dos meios de comunicação de massa não se encontra separada do modo de produção industrial, da lógica da mercadoria e do encantamento proporcionado pelas técnicas, suas linguagens e envolvimento.

A produção da notícia requer, inexoravelmente, algumas variáveis que acusam a impossibilidade dela ser uma expressão objetiva da realidade. Todo fato se expressa pela tensão entre supressão ou destaque. A técnica narrativa derivada do modelo americano, conhecida como pirâmide invertida, representa a separação temporal entre captação informativa e seqüência de exposição, de tal ordem que a organização interna da notícia incorpora a racionalidade técnica presente num sistema que requer agilidade, objetividade, precisão.

A definição da pauta (assuntos cobertos em determinada edição), a fragmentação da informação, incluindo a registrada pela criação de editoriais, a síntese presente nos títulos e nos recursos gráficos, dentre outros aspectos, expressam formas de racionalização do processo informativo. A padronização dos critérios para definir fatos tidos como relevantes socialmente perpassa estruturas centradas em poucas agências de notícia, só para mencionar a desigualdade do fluxo de informações internacionais. A "agenda-setting" se configura pela articulação de meiosimpressos, televisivos, 
radiofônicos, incluindo o suporte da Internet, que tendem a destacar as mesmas fontes, os mesmos assuntos, as mesmas imagens etc.

$M$ arcondes Filho (1989) aponta para o seguinte aspecto: a informação jornalística propende à sensacionalização dos fatos sociais, à personificação dos acontecimentos históricos, à redução do real ao fatual, à extremada fragmentação, descontinuidade e montagem da realidade noticiada. Estas ações procuram exacerbar, com persistência e de forma articulada, a emoção da audiência em torno da estética da mercadoria notícia. 0 efeito adquire verossimilhança com o real muito em decorrência do frenesi informativo, dos constantes estímulos multisensoriais e da inexistência de tempo para o distanciamento crítico. A estrutura não-dialógica dos veículos de comunicação de massa favorece ainda mais a cisão entre a compre ensão dos fatos e a forma fetichizada de sua representação.

É exatamente nesta busca do efeito e da apreensão da audiência pelo espetáculo que $\mathrm{H}$ orkheimer e Adorno assinalam a anomalia de uma sociedade, cujos indivíduos se encontram dessensibilizados frente à repetição da barbárie. A exposição continuada de violências sígnicas elimina o choque, a capacidade da audiência reagir e de se indignar diante do grotesco.

No jornalismo, há um ambiente favorável à estetização da violência. Perseguindo o objetivo de ampliar o espectro de receptores, na perspectiva apresentada por M orin (1986), os meios de comunicação buscam a criação de públicos medianos, universais. A massificação da mensagem tem uma correspondência direta com a facilitação do conteúdo. Em outros termos: uma falsa democratização presente na ilusão de que todos podem ter acesso às mesmas mensagens.

A estética da violência também pode ser identificada nos fait divers, nesta busca tresloucada pelo anômalo. A exploração de crimes, do bizarro, de fatos que mexem com a curiosidade e emoção, acompanhada de narrativas que utilizam os melhores recursos da imagem, expressa bem a possibilidade de esclarecimento pelo acesso à informação jornalística.

A categoria estetização da violência já supõe a idéia de mediação da tecnologia como extensão sensorial, para utilizar uma conhecida expressão de M CLuhan, ou seja, a percepção humana cada vez mais se dá pela influência e mediação da tecnologia. Estetizar significa construir uma realidade que se configure como espetáculo. Até mesmo a violência de uma imagem forte, nos telejornais, por exemplo, tem maior capacidade de criar o desejo pela sua repetição, que propriamente mobilizar sentimentos de indignação, dor. Como num filme de ficção, 
a repetição da violência como espetáculo não requer da audiência outra representação que vá além do fato de ser entretenimento, momento de distração e de prazer.

D estaca M arcondes Filho (1989, p. 149), ao definir notícia:

N otíciaéa informação transformada em mercadoria com todos os seus apelos estéticos, emocionaisesensacionais; paraisto a informação sofreum tratamento quea adapta àsnormas mercadológicas de generalização, padronização, simplificação enegação do subjetivismo. Além do maiséum meio de manipulação ideológica degrupos de poder social euma forma de poder político.

A irracionalidade presente nesta forma de organizar o fato noticioso, ainda mais podendo contar com a disponibilidade de recursos técnicos que fracionam o real, tornando-o quase a expressão de um drama romanesco, também se verifica na seguinte contradição: a da existência de fluxos intensos de informação e a incapacidade da audiência agir diretamente sobre os fatos. M erton e Lazarsfeld, quando escrevem o ensaio "Comunicação de massa, gosto popular e a organização social", em 1948, apontam, na perspectiva da Teoria Funcionalista, esta incongruência da informação estar disponível, mas sem ligação com a ação social organizada.

\section{M ediação da técnica e prejuízos da experiência}

Com o propósito de destacar os prejuízos da mediação da técnica no estatuto da experiência e da sensibilidade, torna-se estratégico assinalar, à maneira de Walter Benjamin, a idéia expressada no ensaio " $\mathrm{A}$ obra de arte na época de sua reprodutibilidade técnica", iniciado em 1936, a respeito da sensibilidade humana não decorrer apenas da natureza, mas também das transformações empreendidas no processo histórico de hominização.

A indústria cultural não somente cria um objeto para o sujeito, como cria este na condição de objeto, para parafrasear M arx. Isto é, uma condição de poder político na sociedade contemporânea que se articula com a criação de necessidades, incluindo as de natureza informativa e aquelas que conduzem ao consumo desenfreado de mercadorias, subvertendo a lógica entre ser e ter. Aqui pretendemos destacar o seguinte: a mediação da técnica estende e acomoda nossa sensibilidade a um mundo que aparentemente reconhecemos como familiar, sem mais o estranhamento das personagens kafkanianas, tão imprescindíveis para acusar a existência de uma vida administrada e impessoal. 
0 controle das necessidades e a mediação da tecnologia agem para estabelecer uma segunda natureza no homem: a de estar ambientado à transmissão de artefatos culturais que incidem na formação prejudicada, pois a diferenciação, aquilo que torna o sujeito capaz de refletir sobre sua condição de não-objeto, acaba sendo minada. A indústria cultural privilegia o momento de adaptação do sujeito à realidade e busca a falsa identidade entre o particular e o universal. Sentir-se integrado, eis a marca da pseudo-individualidade.

De acordo com M arcondes Filho (1993), a era da técnica está marcada pela presentificação. A capacidade de editar, mutilar os acontecimentos e recolocá-los montados numa outra ordem cronológica faz com que a historicidade dos fatos se esgote no momento presente. A vertigem do imediato e a quebra da lógica dos acontecimentos entre si contribuem para afirmar a existência de um mundo cindido. 0 que tem importância é a sensação calculada do perecimento da informação como mercadoria, para rapidamente cair no esquecimento quando outra mais sensacional vier a lhe substituir.

A mediação tecnológica provoca a substituição da experiência autêntica, compreendida quando o sujeito interpela e age sobre os acontecimentos, e no lugar provoca sensível perda da memória involuntária, esta expressão benjaminiana para falar das recordações que nos remetem, inconscientemente, à memória individual. Seria insensato supor que a memória coletiva, que é construída pelos mass media, de todo, compromete a experiência, contudo ocorre uma perda no processo de sua continuidade frente à informação pontual e efêmera. A experiência que está associada, em Benjamin, à duração do tempo, nas mediações tecnológicas se desemboca na vivência do instante.

A exclusão da informação no âmbito da experiência individual, a impessoalidade no processo comunicativo, a repetição, o detalhamento daquilo que é fungível, que revela a existência de um jornalismo minimalista, apontam para um modelo de formação cultural que mina a resistência, a diferença.

\section{M ediação tecnológica e formação}

A mediação tecnológica, que é demarcada pela separação entre processo de produção de bens simbólicos, meios de transmissão e distanciamento no momento de apreensão e sua decodificação, coloca-se como condição estrutural para redimensionar as relações intersubjetivas e intragrupais. A ação sistemática, permanente e continuada das novas 
tecnologias de comunicação que, no dizer de M cLuhan (1969), se portam como extensões sensoriais do homem, não apenas responde pelo aumento do fluxo de informações, mas incide decisivamente nas formas de percepção, inteligibilidade e nas formas de representação do real.

Esta condição das novas tecnologias se firmarem como instância mediadora no campo da percepção e da inteligência coletiva deve ser compreendida como alteração que se estende para a definição da escala das necessidades humanas, em particular, no que se refere ao campo de atenção social às informações que circulam e que submetem a experiência individual e do grupo às referências dos modelos produzidos pelos mass media. Os aparatos comunicacionais agem como meios de adaptação à lógica sistêmica da produção e circulação de mercadorias. O s instrumentos de facilitação deste processo estão associados aos mecanismos de repetição, estandardização e exclusão do novo, identificados por Adorno e H orkheimer, na Dialética do esclarecimento, como constituintes da forma como a indústria cultural modela o processo de recepção de suas mensagens.

Um paradoxo deve ser explicitado: 0 aparecimento da indústria cultural ampliou os canais de produção e de acesso universalizado de informações, que se tornam híbridas (imagens, infografias, som, movimento, grafia etc.) e multisensoriais, o que pode supor imediatamente "progresso" na escala de criação e difusão de conhecimentos. Esta aparente etapa, que desloca para a tecnologia as potencialidades da comunicação humana, não é acompanhada de autêntica autonomia cultural.

O s fluxos de informação, em grande medida, isto não quer dizer que se torna uma dimensão radicalmente única, passam por processos de seleção e exclusão, tendem à espetacularização para se destacar ante a descontinuidade e profusão de mensagens. A heteronomia se porta como indicador da apropriação dos veículos de forma desigual entre os grupos sociais e a demarcação da volatilidade das mensagens caracteriza o momento de destaque para 0 valor de troca da mensagem. 0 transitório e 0 fait divers se instauram como uma condição entranhada na estrutura de produção da mensagem, cuja estética incorpora a dinâmica do processo industrial e da organização societária.

Em nossa Tese de D outoramento, destacamos o seguinte:

Trata-se de uma condição inerenteà produção da notícia em função das condiçõesindustriais da produção jornalística edo fato de queela buscanaturalmentea sen sacionalização dosfatos sociais. 0 conteúdo exploratório do espetacular enquanto elemento constitutivo danotícia se conforma àsformas de produção 
que propiciaa fragmentação, desmontagem, aceleração do processo deprodução e consumo deinformações, queno seu conjunto favorecem a distorção, 0 falseamento da real idade, a exposição cindida dosfatos (Costa, 1999, p. 2).

A Teoria Crítica, ao fazer uma análise estrutural do processo de produção e de recepção de mensagens da indústria cultural, e por favorecer uma interpretação de que os conteúdos não se definem por si, já que a forma de organização do artefato noticioso e sua contingência moldada ao ritmo das rotativas refletem sobre sua significação, torna-se uma referência epistemológica estratégica para interpretar a relação entre produção da cultura e estruturas societárias do capitalismo tardio. I dentificar aspectos da cultura danificada e do processo de padronização estética dos artefatos, a partir desta referência, representa uma reflexão no campo da formação dos indivíduos na sociedade contemporânea.

A contribuição da Teoria Crítica para a educação passa pela investigação sobre a mediação das novas tecnologias na percepção e (des)sensibilização humanas, num contexto onde o fluxo de informação pode se dar de forma desenraizada e descolada da experiência, com capacidade para subverter a noção de duração, continuidade e representação. Esta circunstância moldada pela obsolescência das mercadorias simbólicas e pelo minimalismo de informações descartáveis encontra uma contiguidade com a diminuição da capacidade de pensar e agir com autonomia.

Como afirma Horkheimer (1974, p. 233), "os sentidos humanos são pré-formados de dois modos: pelo caráter histórico do objeto percebido e pelo caráter histórico do órgão perceptivo. Ambos não estão constituídos naturalmente, já que são formados pela atividade humana". N esse contexto, a definição de necessidade informativa e dos padrões de consumo cultural, que envolvem a sedução da imagem, a insistência da repetição publicitária e a urgência da notícia como espetáculo, explicitam 0 modelo de homem construído neste ambiente de progresso tecnológico.

\section{Consideração final}

A revitalização do potencial teórico da Escola de Frankfurt se justifica para os estudos da comunicação, em particular, pela permanência de estruturas concentradas no processo de produção da cultura, que tende a separar o momento de concepção do momento de recepção massiva. 0 surgimento de novos suportes técnicos não criou ainda um ambiente favorável para a realização dos ideários humanistas e nem a técnica, com toda sua sofisticação, foi capaz de gerar uma sociedade esclarecida. 
A crítica negativa, como método de investigação e compreensão da realidade, permite localizar nos novos processos de comunicação estruturas autoritárias. A filosofia, a abordagem sociológica no campo da educação, a aproximação com a literatura e a estética, a maneira de trabalhar com aforismas que permitem tensionar teoria e prática, tão próximas da construção do pensamento frankfurtiano, favorecem pensar fenômenos da comunicação numa perspectiva dialética e inclusiva de várias áreas de conhecimento.

Recebido para publicação em agosto de 2001.

\section{Aesthetic barbarism and JOURnalistic production: THE UPDATE OF THE CULTURE INDUSTRY CONCEPT}

ABST RACT: This work intends, through the update of the concept of culture industry, to demonstrate the contributions of the C ritical Theory to the communication studies, especially regarding the identification of the cultural heteronomy process, thehierarchical arrangement of artifacts and the globalization of aesthetic standards. It takes the journalistic production as a reference to verify the appropriation of the technical rationalization in the construction of the news, and exploresthe violence issue taking into consideration the fact that this subject doesn't drain away at the moment of itsmessage enunciation, but must also beunderstood under the conditions of its production. The technol ogical intervention in the perception of reality and the relationship between sensitiveness and experience complement the exposition.

Key words: Critical Theory; Culture Industry; Aesthetics of violence; $\mathrm{N}$ ews; Cultural background.

\section{Referências bibliográficas}

AD O RN O, Theodor W. "A Indústria Cultural". Trad. de Amélia Cohn. In: CoHn, Gabriel (O rg.), Comunicação de massa e Indústria Cultural, 4a ed., São Paulo: Companhia Editora N acional, 1978.

ADORNO, Theodor W. \& HORKHEIMER, Max. Dialética do esclarecimento - Fragmentos filosóficos. Trad. de Guido de Almeida. Rio de Janeiro: Zahar Editor, 1985.

AD O RN O, Theodor W. Teoria estética. Trad. de Artur M orão. Lisboa: Edições 70, 1988. 
Educação após Auschwitz. Trad. de Wolfgang Leo M aar. São Paulo: Paz \& Terra, 1995.

Teoria da semicultura. Trad. de Newton Ramos-de-O liveira, Bruno Pucci e Cláudia B. M oura Abreu (revisão pelos autores, com a colaboração de Paula Ramos-de-O liveira). Educação \& Sociedade, Campinas: Papirus, dez. 1996, ano 17, oo 56.

BEN JAM IN , Walter. "A obra de arte na época de sua reprodutibilidade técnica". Trad. de Carlos N elson Coutinho. In: Costa LimA, Luiz, Teoria da cultura de massa, 4a. ed., Rio de Janeiro: Paz \& Terra, 1990.

Teses sobre Filosofia da H istória. In: Walter Benjamin - Sociologia, trad. e org. de Flávio R. Kothe, $2^{a}$ edição. São Paulo: Ática, 1991.

Experiência e pobreza. In: 0 bras Escolhidas (Vol. I), trad. de Sérgio Paulo Rouanet, 6ạ ed., São Paulo: Brasiliense, 1993.

COH N, Gabriel (O rg.). Comunicação de massa e indústria cultural. 4a ed., São Paulo: Companhia Editora Nacional, 1978.

COSTA LIMA, Luiz (O rg.). Teoria da cultura de massa. 4ª ed., Rio de Janeiro: Paz \& Terra, 1990.

COSTA, Belarmino Cesar. G. da. 0 'Estado' da educação na 'Folha' de jornal - Como os jornais de grande circulação abordam a questão educacional. D issertação de mestrado, Universidade Federal de São Carlos (U fscar), São Carlos (SP), 1993.

"Jornalismo impresso: Conceito de notícia e a técnica de fetichização dos fatos". In: M ARques de M elo, José (O rg.), Transformações do jornalismo brasileiro - Etica e técnica. São Paulo: Intercom, 1994.

Indústria cultural: Análise crítica e suas possibilidades de revelar ou ocultar a realidade. Petrópolis/São Carlos: Vozes/Edufscar, 1995.

Estética da violência: Jornalismo e produção de sentidos. Tese de D outorado, Unicamp, Campinas, 1999.

EC O, U mberto. A pocalípticos e Integrados. Trad de Pérola Carvalho. São Paulo: Perspectiva, 1970. 
ERBO LATO, M ário. T écnicas de codificação em jornalismo - Redação, captação e edição no jornalismo. $5^{\text {a }}$ ed., São Paulo: Ática, 1991.

HORKHEIMER, M ax. "Teoría tradicional Y teoria crítica". In: Teoria crítica - M ax Horkheimer, trad. Edgardo Albizu y Carlos Luis. Buenos Aires: Amorrortu Editores, 1974.

Eclipse da razão. Trad. de Sebastião U choa Leite. Rio de Janeiro: Editorial Labor do Brasil, 1976.

\& ADORNO, Theodor W. "A indústria cultural: 0 Iluminismo como mistificação das massas". Trad. de Júlia Elisabeth. In: Costa LıM A, Luiz (O rg.), Teoria da Cultura de M assa, 4a ed., Rio de Janeiro: Paz \& Terra, 1990.

LÉVY, Pierre. As tecnologias da inteligência - 0 futuro do pensamento na era da informática. Trad. de Carlos I rineu da Costa. Rio de Janeiro: Editora 34, 1994.

LU STOSA, Elcias. 0 texto da notícia. Brasília: Editora da UnB, 1996.

MARCONDES FILHO, Ciro. 0 capital da notícia - Jornalismo como produção social da segunda natureza. 2a ed., São Paulo: Ática, 1989.

. MARCONDES FILHO, Ciro (O rg.). Pensar - Pulsar: Cultura comunicacional, tecnologias, velocidade/C oletivo N TC. São PauIo: Edições N TC, 1996.

M ARCUSE, H erbert. I deologia da sociedade industrial. Trad. de Giasone Rebuá, Rio de Janeiro: Zahar Editores, 1967.

M CLUH AN, M arshall. Os meios de comunicação como extensões do homem. Trad. de D écio Pignatari. São Paulo: Cultrix, 1969.

MERTON, Robert K. \& LAZARSFELD, Paulo F. "Comunicação de massa, gosto popular e a organização da ação social". Trad. de Carmem D ora Guimarães. In: LıM A, Luiz Costa (0 rg.), Teoria da cultura de massa, Rio de Janeiro: Paz \& Terra, 1990.

M ORIN, Edgar. Cultura de massas no Século XX - Vol. 1: N eurose. Trad. de M aura Ribeiro Sardinha, $8^{a}$ ed. (edição brasileira de 0 espírito do tempo), Rio de Janeiro: Forense Universitária, 1990.

PU CCI, Bruno (O rg.). Teoria crítica e educação - A questão da formação cultural na Escola de Frankfurt. Petrópolis/São Carlos: Vozes/ Edufscar, 1995. 
"A Teoria da semicultura e suas contribuições para a Teoria Crítica da educação". In: Zuın, Antônio Álvaro Soares, Puccı, Bruno \& Ramos-D E-O liveira, N ewton (O rgs.), A educacão danificada - Contribuições à Teoria Crítica da educação. Petrópolis/São C arlos: Vozes/Edufscar, 1998.

RAM O S-DE-O LIVEIRA, N ewton. "R eflexões sobre a educação danificada". In: ZuIN, Antônio Álvaro Soares, Puccl, Bruno \& RAmos-D E-O liveira, N ewton (O rgs.), A educação danificada - Contribuições à Teoria Crítica da educação. Petrópolis/São Carlos: Vozes/Edufscar, 1998. 